This item was submitted to Loughborough's Research Repository by the author.

Items in Figshare are protected by copyright, with all rights reserved, unless otherwise indicated.

\title{
Tin whisker mitigation by means of a post-electroplating electrochemical oxidation treatment
}

\section{PLEASE CITE THE PUBLISHED VERSION}

http://dx.doi.org/10.1080/00202967.2015.1117258

\section{PUBLISHER}

(C) Maney Publishing. Published on behalf of the Institute of Metal Finishing (IMF)

\section{VERSION}

AM (Accepted Manuscript)

\section{PUBLISHER STATEMENT}

This work is made available according to the conditions of the Creative Commons Attribution-NonCommercialNoDerivatives 4.0 International (CC BY-NC-ND 4.0) licence. Full details of this licence are available at: https://creativecommons.org/licenses/by-nc-nd/4.0/

\section{LICENCE}

CC BY-NC-ND 4.0

\section{REPOSITORY RECORD}

Haspel, D., Mark A. Ashworth, L. Wu, G.D. Wilcox, and Roger J. Mortimer. 2015. "Tin Whisker Mitigation by Means of a Post-electroplating Electrochemical Oxidation Treatment". figshare. https://hdl.handle.net/2134/19834. 


\title{
Tin whisker mitigation by means of a post-electroplating electrochemical oxidation treatment
}

\author{
D.M. Haspel ${ }^{1,3}$, M.A. Ashworth ${ }^{1}$, L. Wu ${ }^{1}$, G.D. Wilcox ${ }^{1}$ and R.J. Mortimer ${ }^{2}$ \\ 1.-Department of Materials, Loughborough University, Loughborough, Leicestershire, LE11 \\ 3TU, UK.
}

2.-Department of Chemistry, Loughborough University, Loughborough, Leicestershire, LE11 3TU, UK.

3.-e-mail: d.haspel@lboro.ac.uk

\section{Abstract}

There are very few studies that have investigated directly the effect of an oxide film on tin whisker growth, since the 'cracked oxide theory' was proposed by Tu in $1994^{1}$. The current study has investigated the effect of an electrochemically produced oxide on tin whisker growth, for both $\mathrm{Sn}-\mathrm{Cu}$ electrodeposits on $\mathrm{Cu}$ and pure $\mathrm{Sn}$ electrodeposits on brass. X-ray photoelectron spectroscopy (XPS) has been used to investigate the effect of the applied electrochemical oxidation potential on the oxide film thickness. Focused ion beam (FIB) has been used to prepare cross sections from electrodeposited samples to investigate the influence of the electrochemically formed oxide film on deposit microstructure during longterm room temperature storage. The XPS studies show that the thickness of electrochemically formed oxide film is directly influenced by the applied potential and the total charge passed. Whisker growth studies show that the electrochemical oxidation treatment mitigates whisker growth for both $\mathrm{Sn}-\mathrm{Cu}$ electrodeposits on $\mathrm{Cu}$ and pure $\mathrm{Sn}$ electrodeposits on brass. For Sn electrodeposits on brass, the electrochemically formed oxide greatly reduces both the formation of zinc oxide at the surface and the formation of intermetallic compounds, which results in the mitigation of tin whisker growth. For Sn-Cu electrodeposits on $\mathrm{Cu}$, the electrochemically formed oxide has no apparent effect on intermetallic compound formation and acts simply as a physical barrier to hinder tin whisker growth.

Key words: Tin, electrochemical oxidation, electrodeposition, whisker growth, intermetallic compounds 


\section{Introduction}

A tin whisker is a growth of pure tin that is commonly in the form of a filament, which can grow up to a few millimetres in length, from a thin tin coating (around 0.5-50 $\mu \mathrm{m}$ thick) that has been electroplated onto a substrate ${ }^{2}$. The incubation period prior to the growth of a whisker is uncertain and it is this unpredictability that causes concern to the reliable operation of electronic components ${ }^{3}$. At the current time, there is no one widely accepted mechanism for why and how whiskers grow; though there are number of theories and some commonly agreed factors that affect the growth of tin whiskers ${ }^{2,4,5}$.

Whisker growth has been shown to cause major reliability problems in high value, long term electronics, such as satellites and rocket systems, mainly due to these whiskers growing from one surface and then coming into contact with another, adjacent surface, resulting in a short circuit and subsequent electronic failure. Circuits can also short by long filament type whiskers breaking off and landing across adjacent terminals. Both of these types of failures occur at low currents. At high currents the whiskers can volatilise, which causes a conductive metal gas, which in turn can create a metal vapour arc reaction ${ }^{6}$. This metal vapour arc can generate such high temperatures that it can melt metals and incinerate polymers.

Until recently, whisker growth was successfully mitigated by alloying tin with lead ${ }^{7,8}$. However, restrictions on the use of lead, as result of EU legislation (RoHS), have led to a renewed interest in finding alternative mitigation strategies. There are a number of different mitigation techniques that are currently used to combat this problem, including post-electroplating annealing, alloying, applying a polymeric conformal coating to act as a physical barrier and the use of a nickel underlay to prevent intermetallic formation. ${ }^{9}$

There has been very little research on the role of the oxide layer in whisker growth. The cracked oxide theory proposed by $\mathrm{Tu}^{1,10,11}$ suggested that the tin oxide film played a critical role in the growth of tin whiskers and that a very thick oxide would physically block the growth of filament whiskers or hillocks by reducing the risk of localised oxide cracking. For whiskers to grow, it is first necessary to break the oxide film at weak points and from these, the whiskers will subsequently grow to relieve stress ${ }^{12,13}$. It was suggested by Chang and Vook $^{14}$ that no whiskers will grow in the absence of an oxide film as the deposit would be 
able to relieve internal stress by uniform creep of tin atoms to the deposit surface. However, Moon et $a l^{15}$ later showed that whisker growth occurred on $\mathrm{Sn}-\mathrm{Cu}$ electrodeposits that had been stored for 9 days under vacuum with the surface oxide initially removed by ion beam sputtering. A recent study carried out by Su et $a l^{16}$ showed the importance of weak points in the oxide, by using $200 \mathrm{~nm}$ thick sputter deposited tin oxide films with pre-defined arrays of weak spots built into the oxide film using lithography. It was observed that an increased number of whiskers grew from samples that had a greater number of weak spots.

in a previous study ${ }^{17}$ the authors presented some initial results, which indicated that whisker growth could be reduced by the application of an electrochemical oxide film. The current paper builds upon this initial work to more fully investigate the influence of applied potential and charge passed on the oxide film developed and its effect on whisker growth. The effect of the electrochemical oxide treatment on the development of the deposit microstructure during long-term storage is also investigated to more fully understand the mechanism by which whisker growth is mitigated.

\section{Experimental}

\subsection{Electrodeposition of Tin}

Pure Sn was electrodeposited onto both Cu (Advent Research Materials, 99.9\%, $0.1 \mathrm{~mm}$ and $0.4 \mathrm{~mm}$ thickness) and brass (Goodfellow, 63\% Cu/37\% Zn, $0.38 \mathrm{~mm}$ thickness) substrates, using a bright acid Sn electroplating solution. A Sn-Cu alloy was also electroplated onto $\mathrm{Cu}$ for whisker growth trials. The electroplating solution contained $60 \mathrm{~g} \mathrm{~L}^{-1}$ tin sulphate (Sigma Aldrich), $70 \mathrm{ml} \mathrm{L}^{-1}$ sulphuric acid (Fisher Scientific) and $40 \mathrm{ml} \mathrm{L}^{-1}$ Tinmac Stannolyte (MacDermid), a propriety additive that acts as a brightener. Electrodeposition of $2 \mu \mathrm{m}$ and 5 $\mu \mathrm{m}$ pure Sn onto $\mathrm{Cu}$ and brass was carried out using a current density of $20 \mathrm{~mA} \mathrm{~cm}^{-2}$. For the electrodeposition of $\mathrm{Sn}-\mathrm{Cu}$ alloys the $\mathrm{Sn}$ electroplating bath was modified by the addition of $\mathrm{Cu}$ ions at a concentration of $10 \mathrm{mmol} \mathrm{L}^{-1}$, using $\mathrm{Cu}$ sulphate. Electrodeposition of $2 \mu \mathrm{m} \mathrm{Sn}$ $\mathrm{Cu}$ onto $\mathrm{Cu}$ was carried out using a current density of $10 \mathrm{~mA} \mathrm{~cm}$, which resulted in a uniform electrodeposit with a Cu content of $1 \mathrm{wt} \%$.

The test coupons used had dimensions of $2 \times 4 \mathrm{~cm}$ and were masked with chemically resistant tape to result in an electroplated area of $2 \times 2 \mathrm{~cm}$. Larger test coupons with 
dimensions $4 \times 6 \mathrm{~cm}$ and an electroplated area of $4 \times 4.5 \mathrm{~cm}$ were used for whisker growth studies. The coupons were used in the as-supplied condition with no additional polishing or grinding. Electrodeposition of pure Sn was carried out using a 99.95\% Sn foil anode (Advent Research Materials, $0.25 \mathrm{~mm}$ ), whilst electrodeposition of the $\mathrm{Sn}-\mathrm{Cu}$ was carried out using a platinised titanium mesh anode. Immediately prior to electrodeposition, all the coupons were degreased using acetone (Fisher Scientific), pickled for $60 \mathrm{~s}$ in a $20 \% \mathrm{v} / \mathrm{v}$ solution of sulphuric acid (SG 1.83, Fisher Scientific), rinsed in deionised water and dried using hot air. The thickness of pure Sn electrodeposits was $5 \mu \mathrm{m}$ for cyclic voltammetry and electrochemical oxidation trials. The thickness of pure $\mathrm{Sn}$ and $\mathrm{Sn}-\mathrm{Cu}$ electrodeposits was 2 $\mu \mathrm{m}$ for whisker growth studies.

\subsection{Preparation of the Electrolyte Solution for Tin Oxidation}

For the electrochemical oxidation of the Sn electrodeposits two solutions were selected, a $\mathrm{pH} 8.9$ potassium bicarbonate-potassium carbonate solution $\left(0.75 \mathrm{~mol} \mathrm{~L}^{-1}\right.$ of potassium bicarbonate, Sigma Aldrich, and $0.05 \mathrm{~mol} \mathrm{~L}^{-1}$ of potassium carbonate, Sigma Aldrich) and a $\mathrm{pH} 8.4$ borate buffer solution $\left(9.55 \mathrm{~g} \mathrm{~L}^{-1}\right.$ sodium borate, Sigma Aldrich, and $6.18 \mathrm{~g} \mathrm{~L}^{-1}$ boric acid, Sigma Aldrich). Both electrolyte solutions were prepared using deionised water and the $\mathrm{pH}$ was adjusted to the required value, using additions of sodium hydroxide (Fisher Scientific).

\subsection{Cyclic Voltammetry}

Cyclic voltammetry was carried out for Sn electrodeposits in naturally aerated $\mathrm{pH} 8.9$ potassium bicarbonate-potassium carbonate solution to determine the location of the oxidation peaks. Analysis was carried out using a Solartron SI 1286 Electrochemical Interface potentiostat by means of a 3-electrode cell comprising of a static Sn electrodeposit as the working electrode, a saturated calomel reference electrode (SCE) and a platinised titanium mesh counter electrode. The electrode potential was swept from a starting potential of -1.1 $\mathrm{V}$ down to $-1.5 \mathrm{~V}$, reversed up to $1.5 \mathrm{~V}$ and finally returned to $-1.1 \mathrm{~V}$ (all versus SCE) using a linear scan rate of $10 \mathrm{mV} \mathrm{s}^{-1}$.

\subsection{Electrochemical Oxidation of Tin}

Electrochemical oxidation was carried out immediately after tin electrodeposition using a Solartron SI 1286 Electrochemical Interface potentiostat using the 3-electrode cell 
previously described. Following immersion of the coupon into the naturally aerated electrolyte solution, the Sn electrodeposit was initially held at a potential of $-1.5 \mathrm{~V}$ vs. SCE to reduce the pre-existing oxide. When hydrogen evolution was observed the surface was agitated using a pipette to remove the bubbles and the potential was increased to the desired value for oxidation.

\subsection{Characterisation of Electrochemically Formed Oxides}

Two charges were set as limits, $30 \mathrm{mC} \mathrm{cm}^{-2}$ and $60 \mathrm{mC} \mathrm{cm}^{-2}$. The effect of charge passed and oxidation potential on the composition and thickness of the oxide film was investigated by x-ray photoelectron spectroscopy (XPS) using a Thermo-Scientific K-Alpha x-ray photoelectron spectrometer. Sputter depth profiling was carried out using $200 \mathrm{eV}$ argon ions with an estimated etch rate of $\sim 0.01 \mathrm{~nm} \mathrm{~s}^{-1}$. XPS analysis was carried out within 24 hours of electrodeposition and electrochemical oxidation, unless otherwise stated.

\subsection{Characterisation of Tin Deposits}

The effect of an electrochemical oxide film on the microstructural evolution of electrodeposited $\mathrm{Sn}$ and $\mathrm{Sn}-\mathrm{Cu}$ alloys was investigated by means of cross-sections that were prepared by focussed ion beam (FIB) milling, using a FEI Nova 600 Nanolab Dual Beam FIBSEM. Ion beam milling was carried out at a $52^{\circ}$ tilt angle with $30 \mathrm{kV}$ gallium ion beam. Initial trench milling was carried out at $20 \mathrm{nA}$ and the final face milling was carried out at $3 \mathrm{nA}$ with a tilt angle of $53.5^{\circ}$. Ion beam images were acquired using the gallium ion beam at a current of $30 \mathrm{pA}$.

\subsection{Whisker Growth Studies}

The effect of the electrochemically formed oxides on whisker growth was assessed using 2 $\mu \mathrm{m} \mathrm{Sn}$ electrodeposits on brass and $2 \mu \mathrm{m} \mathrm{Sn}-\mathrm{Cu}$ electrodeposits on $\mathrm{Cu}$. For each electrochemical oxidation treatment three identical samples were prepared. After electrodeposition and electrochemical oxidation, the samples were stored at room temperature $\left(\sim 20^{\circ} \mathrm{C}\right)$. The growth of whiskers was studied using both optical microscopy and scanning electron microscopy (SEM). The density of whiskers was measured using an optical microscope with an objective magnification of either $\times 20$ or $\times 10$. SEM analysis was carried out using a Carl Zeiss Leo 1530 VP field emission gun SEM (FEGSEM) and an operating voltage of $10 \mathrm{kV}$. 


\section{Results and Discussion}

\subsection{Development of the Electrochemical Oxide}

Cyclic voltammetry was conducted using a standard potassium bicarbonate-carbonate electrolyte to identify suitable potentials for subsequent electrochemical oxidation trials (figure [1]). Two oxidations peaks (I and II) were recorded at potentials of $-0.83 \mathrm{~V}$ and -0.66 V vs. SCE respectively. Peaks I and II have been attributed previously to the two Sn oxidation states, $\mathrm{Sn}(\mathrm{II})$ and $\mathrm{Sn}(\mathrm{IV})$ respectively ${ }^{18,19}$. However, Díaz et $a \mathrm{l}^{20}$ have also suggested that oxidation peaks I and II both corresponded to the oxidation of Sn to Sn(II).

The potentials chosen for electrochemical oxidation studies, were $-0.66 \mathrm{~V}$ (II), $-0.5 \mathrm{~V}$ (III), $0.4 \vee(I V), 0 \vee(V)$ and $1.2 \vee(V I)$ (all vs. SCE). Oxidation peak I (-0.83 V vs. SCE) was not studied because it had previously been shown to produce an oxide film comparable to a native oxide ${ }^{17}$. The electrochemical oxidation potentials $-0.4 \mathrm{~V}$ and $-0.5 \mathrm{~V}$ vs. SCE were chosen as they occurred upon the broad trailing slope of the second oxidation peak which would suggest large amounts of activity within this region and it was suggested by Drogowska et $a l^{19}$ that this broad slope corresponds to a dehydration reaction that results in the formation of $\mathrm{SnO}_{2}$. The electrochemical oxidation potential of $0 \mathrm{~V}$ vs. SCE was chosen as it occurred on the part of the voltammogram that had the lowest anodic current, which was suggested by Drogowska et $a l^{19}$ to be the region of passivity. The electrochemical oxidation potential of $1.2 \mathrm{~V}$ vs. SCE was chosen as it was previously shown to produce a thick oxide film ${ }^{17}$.

The effect of electrochemical oxidation potential on the Sn oxide thickness, for a charge passed of $30 \mathrm{mC} \mathrm{cm}^{-2}$, is shown in the XPS high resolution scans of the $\mathrm{Sn} 3 \mathrm{~d}$ peak in figure [2]; a high resolution $\mathrm{Sn} 3 \mathrm{~d}$ scan of a native air-formed oxide is also shown for comparison. The relative intensity of the Sn oxide and Sn metal peaks, at $\sim 487 \mathrm{eV}$ and $\sim 485 \mathrm{eV}$ respectively, enables the comparative thickness of the oxide layer to be inferred. It is evident from figure [2] that the native air-formed oxide is very thin compared with oxide films that are formed electrochemically. Results show that the thickest electrochemical oxide film was produced at a potential of $1.2 \mathrm{~V}$ vs. SCE, which is consistent with previous trials $^{17}$. The Sn oxide and Sn metal contributions as a function of electrochemical oxidation 
potential are summarised in table [1], which clearly indicates that the thickness of the Sn oxide increases as the oxidation potential is increased.

Samples with electrochemically formed oxides were analysed using SEM to study the effect of electrochemical oxidation on the surface of the Sn electrodeposit. It is apparent from figure [3] that electrochemical oxidation at certain potentials (e.g. - $0.66 \mathrm{~V}$ vs. SCE) can have a pronounced effect on the surface topography. However, the surface of samples electrochemically oxidised at a potential of $1.2 \mathrm{~V}$ vs. SCE ( $30 \mathrm{mC} \mathrm{cm}$ of charge passed) is indistinguishable from that of a native air-formed oxide. Increasing the amount of charge passed, increases the extent of the surface roughening for samples electrochemically oxidised at a potential of $-0.66 \mathrm{~V}$ vs. SCE (figure [3c]). This may suggest that a Sn dissolution reaction has occurred. The size and shape of the surface features are comparable to that of the Sn grains. Similar features were also observed in an earlier study by Ashworth et $a l^{17}$ for electrochemical oxidation at same the potential.

Further electrochemical oxidation trials were undertaken using the potassium bicarbonatepotassium carbonate solution, at potentials greater than $1.2 \mathrm{~V}$ vs. SCE, in an attempt to increase the electrochemical oxide film thickness. The observed reduction in the intensity of the Sn metal peak with increasing electrochemical oxidation potential (figure [4]) suggests that the oxide film thickness is increased. This is consistent with previous trials by Ashworth et $a l^{17}$ using the same potentials in a borate buffer solution. As the electrochemical oxidation potential was increased from $1.2 \mathrm{~V}$ to $2.0 \mathrm{~V}$ vs. SCE the binding energy of the Sn oxide peak shifted from $487 \mathrm{eV}$ to $486.8 \mathrm{eV}$. However, this does not necessarily indicate a difference in the oxide formed as the binding energies all fall within the binding energy range for $\mathrm{SnO}_{2}{ }^{21}$.

Depth profiling was carried out on each sample to confirm that electrochemical oxidation at potentials above $1.2 \mathrm{~V}$ vs. SCE does increase the thickness of the oxide. The depth profiles in figure [5] confirm that the oxide film increases in thickness with increasing electrochemical oxidation potential. Results show that when electrochemical oxidation is carried out at a potential of $2.0 \mathrm{~V}$ vs. SCE the thickness of the oxide film increases by $\sim 75 \%$ compared with a potential of $1.2 \mathrm{~V}$ vs. SCE. An increase in the thickness of the oxide film should have a beneficial effect on whisker mitigation ${ }^{1,10,11}$. 
The effect of electrochemical oxidation on whisker growth was studied using $2 \mu \mathrm{m} \mathrm{Sn-Cu}$ electrodeposits on $\mathrm{Cu}$ and $2 \mu \mathrm{m}$ Sn electrodeposits on brass. The $\mathrm{Sn}-\mathrm{Cu}$ electrodeposits were oxidised at potentials ranging between $-0.66 \mathrm{~V}$ and $2.0 \mathrm{~V}$ vs. SCE in a potassium bicarbonate-carbonate solution. The Sn electrodeposits on brass were oxidised at potentials ranging between $1.2 \mathrm{~V}$ and $2.0 \mathrm{~V}$ vs. SCE. In each case, control samples were prepared and left to develop native air-formed oxide films.

\subsection{Whisker Growth Studies}

\subsubsection{Sn-Cu electrodeposits on $\mathrm{Cu}$}

For whisker growth studies using $\mathrm{Sn}-\mathrm{Cu}$ electrodeposits on $\mathrm{Cu}$, electrochemical oxidation was carried out at potentials of $-0.66 \mathrm{~V},-0.5 \mathrm{~V},-0.4 \mathrm{~V}, 0.0 \mathrm{~V}$ and $1.2 \mathrm{~V}$ (all versus SCE). Large test coupons were used, which contained three different areas of oxide; two areas were electrochemically oxidised with a different charge passed applied in each area (achieved by sequentially lowering the test coupon into the electrolyte; the other area was left to develop a native air-formed oxide (figure [6]). Whiskers were counted on each area after 2 months of storage and whisker densities were calculated (figure [7]). An important observation is that there is a large difference in the whisker densities for the native oxides, ranging from $\sim 1200 \mathrm{~cm}^{-2}$ to $\sim 3700 \mathrm{~cm}^{-2}$. There are a number of possible explanations for this difference: firstly whisker growth is, by nature, unpredictable and sample to sample variations in whisker density are not uncommon ${ }^{22}$. Secondly, there may be slight variations in the $\mathrm{Cu}$ content of the deposit, due to either $\mathrm{Sn}$ or $\mathrm{Cu}$ depletion since an inert counter electrode is being used and the electroplating bath is not being replenished with fresh metal ions.

For a charge passed of $30 \mathrm{mC} \mathrm{cm}$ electrochemical oxidation at $1.2 \mathrm{~V}, 0 \mathrm{~V}$ and $-0.66 \mathrm{~V}$ vs. SCE (figure [7]) resulted in a reduction in whisker growth. However, electrochemical oxidation at potentials of $-0.4 \mathrm{~V}$ and $-0.5 \mathrm{~V}$ vs. SCE resulted in an increase in whisker density, despite the fact that the oxide film is thicker than that of the native oxide. Further work is planned to investigate the cause of the increased whisker growth.

For a charge passed of $60 \mathrm{mC} \mathrm{cm}$, all of the electrochemical oxide films significantly reduced the whisker density compared with the corresponding native oxide film (figure [7]). This reduction in whisker density is mostly likely due to the presence of a thicker oxide film, 
which would be in agreement with Tu's cracked oxide theory ${ }^{1,10,11}$, which proposed that a thicker oxide would reduce oxide cracking. The reduction in whisker density for samples electrochemically oxidised at potentials of $-0.4 \mathrm{~V}$ and $-0.5 \mathrm{~V}$ vs. SCE suggests that a minimum threshold charge has to be passed before a stable oxide is formed that can reduce whisker growth.

Results show that the greatest whisker mitigation is obtained for samples electrochemically oxidised at potentials of $1.2 \mathrm{~V}$ and $-0.66 \mathrm{~V}$ vs. SCE, both these potentials reduced whisker density at each of the charges passed producing a reduction of over $80 \%$ compared with the corresponding native oxide

For electrochemical oxidation at potentials of $1.2 \mathrm{~V}, 1.6 \mathrm{~V}$ and $2.0 \mathrm{~V}(\mathrm{Vs}$. SCE), samples with an electroplated area of $2 \times 2 \mathrm{~cm}$ were used. Table [2] shows that as the applied oxidation potential is increased, from $1.2 \mathrm{~V}$ to $2.0 \mathrm{~V}$ vs. SCE, the whisker density is further reduced. The reduction in whisker growth can be directly related to the Sn oxide depth profiles in figure [5], which showed that oxidation at potentials greater than $1.2 \mathrm{~V}$ vs. SCE resulted in an increase in oxide thickness. Table [2] also shows that the number of frames (out of 60) where no whiskers were observed was considerably higher for the electrochemically oxidised samples and increased slightly with increasing oxidation potential. The large number of frames with no whiskers present results in a high standard deviation, relative to the measured whisker density, for the electrochemically oxidised samples.

To more fully understand the mechanism by which whisker mitigation is accomplished for the electrochemically oxidised samples, FIB analysis was carried on Sn-Cu electrodeposits on $\mathrm{Cu}$ after storage at room temperature for $\sim 24$ months.

Figure [8] shows FIB cross-sections obtained from two $\mathrm{Sn}-\mathrm{Cu}$ on Cu samples after storage at room temperature for 24 months; the first left to develop a native oxide (figure [8a]) and the second electrochemically oxidised at $1.2 \mathrm{~V}$ vs. SCE in potassium bicarbonate-carbonate (figure [8b]). It can be seen that extensive intermetallic formation has occurred in both samples, i.e. the presence of the electrochemical oxide has had no observable effect on intermetallic growth, which is the primary driving force for whisker growth in these samples ${ }^{8,23,24}$. This suggests that the reduced whisker growth observed for the 
electrochemically oxidised samples results from the thicker electrochemical oxide providing an enhanced physical barrier to the growth of whiskers rather than the driving force for

whisker growth being reduced. This observation supports Tu's theory ${ }^{1,10,11}$, which proposed that a thicker oxide will mitigate whisker growth by acting as a physical barrier and reduce the risk of localised cracking.

XPS depth profiles obtained from the surface of these samples are shown in figure [9], together with a one day old native oxide. After storage at room temperature for $\sim 24$ months the Sn oxide thickness is greatly increased for the sample left to develop the native oxide and is approaching the thickness of the electrochemically oxidised sample. The more gradual reduction in oxygen content with depth for the sample with the native oxide after $\sim 24$ months storage (figure [9b]) indicates that significant inward diffusion of oxygen into the electrodeposit has occurred. In comparison, the oxygen content drops off more rapidly for the electrochemically oxidised sample. This suggests that the electrochemical oxide film may act as a diffusion barrier to prevent the inward diffusion of oxygen into the electrodeposit.

\subsubsection{Sn electrodeposits on brass}

For electrochemical oxidation at potentials of $1.2 \mathrm{~V}, 1.6 \mathrm{~V}$ and $2.0 \mathrm{~V}$ (vs. SCE), samples with an electroplated area of $2 \times 2 \mathrm{~cm}$ were used. Table [3] shows that for $\mathrm{Sn}$ electrodeposits on brass, whisker growth is dramatically reduced by the electrochemical oxidation treatments. Furthermore, as the applied oxidation potential is increased the whisker density is further decreased. The slight reduction in whisker growth at the higher oxidation potentials can be directly related to the relative intensities of the $\mathrm{Sn} 3 \mathrm{~d} 5$ oxide and $\mathrm{Sn} 3 \mathrm{~d} 5$ metals peaks shown in previous work ${ }^{17}$ which indicated that oxidation at potentials greater than $1.2 \mathrm{~V}$ vs. SCE resulted in an increase in oxide thickness.

To more fully understand the whisker mitigation mechanism, FIB analysis was carried on Sn electrodeposits on brass after storage at room temperature for 30 months.

Figure [10] shows FIB cross-sections of two Sn on brass samples, with the first left to develop a native oxide (figure [10a]) and the second with an electrochemical oxide formed at $1.2 \mathrm{~V}$ vs. SCE in borate buffer (figure [10b]). Figure [10a] clearly shows both zinc oxide, at 
the deposit surface, and $\mathrm{Cu}_{6} \mathrm{Sn}_{5}$ intermetallic formation at the Sn-brass interface, both of which are known to cause whisker growth ${ }^{8,17,23-25}$, by generating internal stresses within the electrodeposited coating. In comparison figure [10b] shows that no zinc oxide formation has occurred at the surface of the electrochemically oxidised electrodeposit and only limited intermetallic formation has occurred at the $\mathrm{Sn}-\mathrm{Cu}$ interface after 30 months of storage.

XPS depth profiles obtained from the same samples are shown in figure [11] together with a depth profile, measured after $\sim 24$ hours, from a tin electrodeposit on brass left to develop a native oxide (figure [11a]). Comparison of the samples left to develop native oxides after 1 day and 30 months shows that the amount of zinc and oxygen present at the deposit surface greatly increases, which corresponds to the formation of zinc oxide at the surface. By comparison, zinc diffusion to the surface of the electrochemically oxidised deposit is prevented by the presence of the thicker Sn oxide film, which was produced shortly after the deposition of the $\mathrm{Sn}^{17}$. Since high zinc concentrations are built up beneath the $\mathrm{Sn}$ oxide, but FIB analyses suggest that no zinc oxide is present within the electrochemically oxidised $\mathrm{Sn}$, it may be inferred that the electrochemically formed Sn oxide is preventing the inward diffusion of oxygen atoms into the electrodeposit.

These results demonstrate that the electrochemically formed oxide acts as a diffusion barrier and prevents the formation of zinc oxide at the electrodeposit surface, which prevents the development of internal stresses. The effect of the electrochemical oxidation treatment on the development of the $\mathrm{Cu}_{6} \mathrm{Sn}_{5}$ intermetallic is, perhaps, more surprising, since it was not expected that the electrochemically formed oxide would have an influence on the $\mathrm{Cu}_{6} \mathrm{Sn}_{5}$ intermetallic growth.

\section{Conclusions}

The application of an electrochemical oxidation treatment has been demonstrated to successfully mitigate whisker growth for both $\mathrm{Sn}-\mathrm{Cu}$ deposits on $\mathrm{Cu}$ and pure $\mathrm{Sn}$ deposits on brass.

For $\mathrm{Sn}$ - $\mathrm{Cu}$ deposits on $\mathrm{Cu}$, the presence of the electrochemical oxide has no influence on the principal driving force for whisker growth, i.e. intermetallic formation, and whisker mitigation is derived from the thicker electrochemical oxide providing an enhanced physical 
barrier. The presence of a thicker oxide layer mitigates whisker growth by reducing the risk of localised cracking in the oxide film through which whiskers may subsequently grow.

For electrochemically oxidised pure Sn deposits on brass, whisker mitigation is achieved by preventing the formation of zinc oxide at the deposit surface and also by greatly reducing the growth of $\mathrm{Cu}_{6} \mathrm{Sn}_{5}$ intermetallic at the $\mathrm{Sn}-\mathrm{Cu}$ interface, i.e. the driving forces for whisker growth are diminished. The electrochemical oxide may also function as a physical barrier to whisker growth in a manner analogous to that observed for the Sn-Cu deposits.

The thickness of the electrochemically formed oxide film is directly related to the applied potential and the total amount of charge passed. For an equivalent charge passed, the thickest oxide film, and most effective whisker mitigation, was obtained for samples electrochemically oxidised at the highest potentials studied, i.e. 1.2-2.0 V vs. SCE.

\section{Acknowledgements}

The authors would like to both the UK EPSRC Innovative Electronics Manufacturing Research Centre for funding this research through the WHISKERMIT programme and the Loughborough University Materials Research School.

\section{References}

1. Tu K-N. Irreversible processes of spontaneous whisker growth in bimetallic Cu-Sn thin film reactions. Phys. Rev. 1994;49(3):2030-2034.

2. Galyon GT. Annotated Tin Whisker Bibliography and Anthology. Trans. on Elect. Pack. Manu. 2005;28(1):94-122.

3. Compton KG, Medizza A, Arnold SM. Filamentary growths on metal surfaces - whiskers. Corrosion. 1951;7(10):327-334.

4. Chason E, Jadhav N, Pei F, Buchovecky E, Bower A. Growth of whiskers from Sn surfaces: Driving forces and growth mechanisms. Progress in Surface Science. 2013;88(2):103-131.

5. Zhang P, Zhang YM, Sun ZM. Spontaneous Growth of Metal Whiskers on Surfaces of Solids: A Review. J. Mat. Sci. \& Tech. 2015;31(7):675-698.

6. Han S, Osterman M, Pecht M. Likelihood of Metal Vapor Arc by Tin Whiskers. SMT Magazine. 2012 Aug:48-56. 
7. Arnold SM. Repressing the Growth of Tin Whiskers. Plating. 1966;53(1):96-99.

8. Boettinger WJ, Johnson C, Bendersky L, Moon K, Williams M, Stafford G. Whisker and hillock formation on Sn, Sn-Cu and Sn-Pb electrodeposits'. Acta Materialia. 2005;53(19):5033-5050.

9. Osterman M. Mitigation strategies for tin whiskers. CALCE EPSC. 2002 [accessed 2015 Jun 8]. http://www.calce.umd.edu/tin-whiskers/TINWHISKERMITIGATION.pdf

10. Tu K-N, Zeng K. Reliability Issues of Pb-free Solder Joints in Electronic Packaging Technology. Proceedings of the IEEE Electronic Components and Technology Conference,. 2002:1194-1200.

11. Tu K-N, Chen C, Wu AT. Stress analysis of spontaneous Sn whisker growth. J. Mat. Sci. 2007;18(1-3):269-281.

12. Kumar KS, Reinbold L, Bower AF, Chason E. Plastic deformation processes in $\mathrm{Cu} / \mathrm{Sn}$ bimetallic films. J. Mat. Res. 2008;23(11):2916-2934.

13. Lee BZ, Lee DN. Spontaneous growth mechanism of tin whiskers. Acta Materialia. 1998;46(10):3701-3714.

14. Chang $\mathrm{CY}$, Vook RW. The effect of surface aluminum oxide films on thermally induced hillock formation. Thin Solid Films. 1993;228(1-2):205-209.

15. Moon K-W, Johnson CE, Williams ME, Kongstein O, Stafford GR, Handwerker CA, Boettinger WJ. Observed Correlation of Sn Oxide Film to Sn Whisker Growth in Sn-Cu Electrodeposit for Pb-Free Solders. J. Electron. Mat. 2005;34(9):L31-L33.

16. Su C-H, Chen H, Lee H-Y, Liu CY, Ku C-S, Wu AT. Kinetic Analysis of Spontaneous Whisker Growth on Pret-treated Surfaces with Weak Oxide. J. Electron. Mat. 2014;43(9):3290-3295.

17. Ashworth MA, Haspel D, Wu L, Wilcox GD, Mortimer RJ. An Investigation into the Effect of a Post-electroplating Electrochemical Oxidation Treatment on Tin Whisker Formation. J. Electron. Mat. 2015;44(1):442-456.

18. Alvarez P, Ribotta S, Folquer M. Potentiodynamic behaviour of tin in different buffer solutions. Corr. Sci. 2002;44(1):49-65.

19. Drogowska M, Ménard H, Brossard L. Electrochemical behaviour of tin in bicarbonate solution at pH 8. J. Appl. Electrochem. 1991;21(1):84-90.

20. Díaz R, Díez-Pérez I, Gorostiza P, Sanz F, Morante JR. An Electrochemical Study of Tin Oxide Thin Film in Borate Buffer Solutions. J. Braz. Chem. Soc. 2003;14(4):523-529.

21. NIST. X-ray Photoelectron Spectroscopy Database. NIST Stand. Ref. Database 20, Version 20. [accessed 2015 Sep 3]. http://srdata.nist.gov/xps/ 
22. Ashworth MA, Wilcox GD, Higginson RL, Heath RJ, Liu C, Mortimer RJ. The effect of electroplating parameters and substrate material on tin whisker formation. Microelectronics Reliability. 2015;55(1):180-191.

23. Tu K-N, Suh J, Wu AT-C, Tamura N, Tung C-H. Mechanism and Prevention of Spontaneous Tin Whisker Growth. Mat. Trans. 2005;46(11):2300-2308.

24. Chason E, Jadhav N, Chan WL, Reinbold L, Kumar KS. Whisker formation in Sn and Pb-Sn coatings; Role of intermetallic growth, stress evolution, and plastic deformation processes. Appl. Phys. Lett. 2008;92(17):171901-171901-3.

25. Ashworth MA, Wilcox GD, Higginson RL, Heath RJ, Liu C. An investigation into Zinc diffusion and tin whisker growth for electroplated tin deposits on brass. J. Electron. Mat. 2014;43(4):1005-1016. 
Table [1] The proportion of tin metal and tin oxide species constituting the of $S n 3 d_{5 / 2}$ peak as function of the applied electrochemical oxidation potential, showing the proportion of tin metal with tin oxide

\begin{tabular}{|c|c|c|}
\hline \multirow{2}{*}{$\begin{array}{c}\text { Sample Treatment } \\
\text { V vs. SCE }\end{array}$} & \multicolumn{2}{|c|}{ Proportion of Species } \\
\hline & Tin metal \% & Tin oxide $\%$ \\
\hline Native air-formed & 33 & 67 \\
\hline$-0.66 \mathrm{~V}$ & 23 & 77 \\
\hline$-0.5 \mathrm{~V}$ & 25 & 75 \\
\hline$-0.4 \mathrm{~V}$ & 20 & 80 \\
\hline $0 \mathrm{~V}$ & 16 & 82 \\
\hline $1.2 \mathrm{~V}$ & 4 & 96 \\
\hline $1.6 \mathrm{~V}$ & 2 & 98 \\
\hline $2.0 \mathrm{~V}$ & 1 & 99 \\
\hline
\end{tabular}


Table [2] Measured whisker densities for electrochemically oxidised $2 \mu \mathrm{m}$ Sn-Cu electrodeposits on Cu after 4 weeks of storage at room temperature

\begin{tabular}{ccc}
$\begin{array}{c}\text { Oxidation potential } \\
\text { V vs SCE }\end{array}$ & $\begin{array}{c}\text { Average number of } \\
\text { whiskers per cm }\end{array}$ & $\begin{array}{c}\text { Number of frames } \\
\text { with no whiskers } \\
\text { (out of 60) }\end{array}$ \\
\hline Native & $264 \pm 136$ & 3 \\
$1.2 \mathrm{~V}$ & $59 \pm 65$ & 23 \\
$1.6 \mathrm{~V}$ & $37 \pm 50$ & 32 \\
$2.0 \mathrm{~V}$ & $33 \pm 49$ & 34
\end{tabular}


Table [3] Measured whisker densities for electrochemically oxidised $2 \mu \mathrm{m}$ Sn electrodeposits on brass after 36 months of storage at room temperature

\begin{tabular}{ccc}
$\begin{array}{c}\text { Oxidation potential } \\
\text { V vs SCE }\end{array}$ & $\begin{array}{c}\text { Average number of } \\
\text { whiskers per } \mathrm{cm}^{2}\end{array}$ & $\begin{array}{c}\text { Number of frames } \\
\text { with no whiskers } \\
\text { (out of 60) }\end{array}$ \\
\hline Native & $1489 \pm 681$ & 0 \\
$1.2 \mathrm{~V}$ & $9 \pm 21$ & 50 \\
$1.6 \mathrm{~V}$ & $7 \pm 18$ & 51 \\
$2.0 \mathrm{~V}$ & $5 \pm 16$ & 54
\end{tabular}




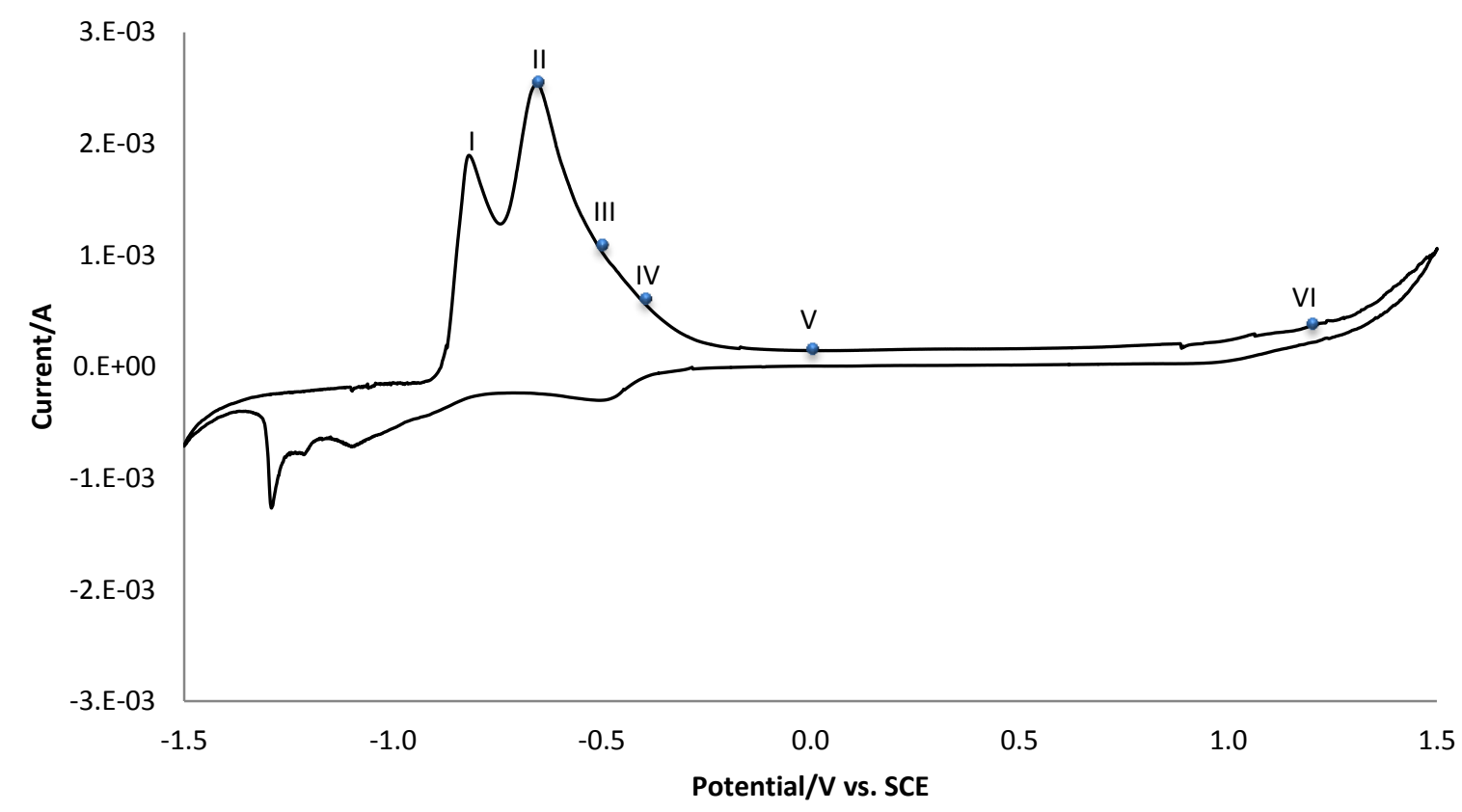

Figure [1] A cyclic voltammogram for electroplated tin on copper with a thickness of $5 \mu \mathrm{m}$ in a potassium bicarbonate-carbonate oxidising bath at a scan rate of $10 \mathrm{mV} \mathrm{s}^{-1}$ 
a) $1.2 \mathrm{~V}$

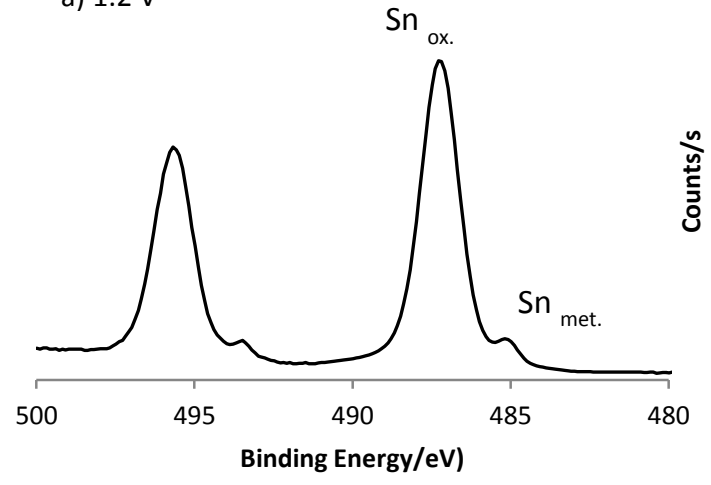

c) $-0.4 \mathrm{~V}$

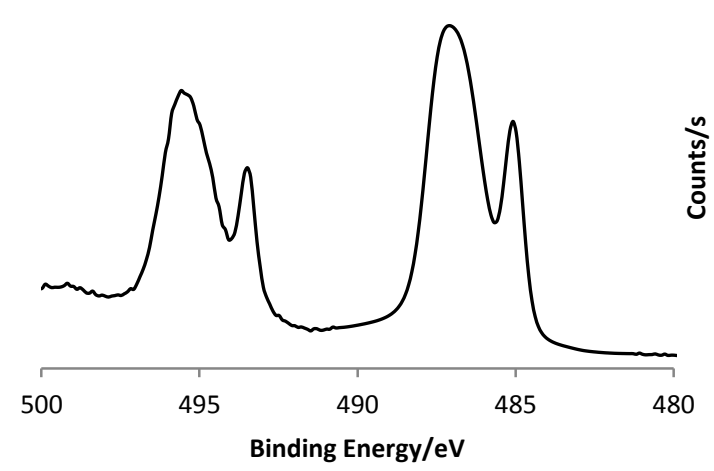

e) $-0.66 \mathrm{~V}$

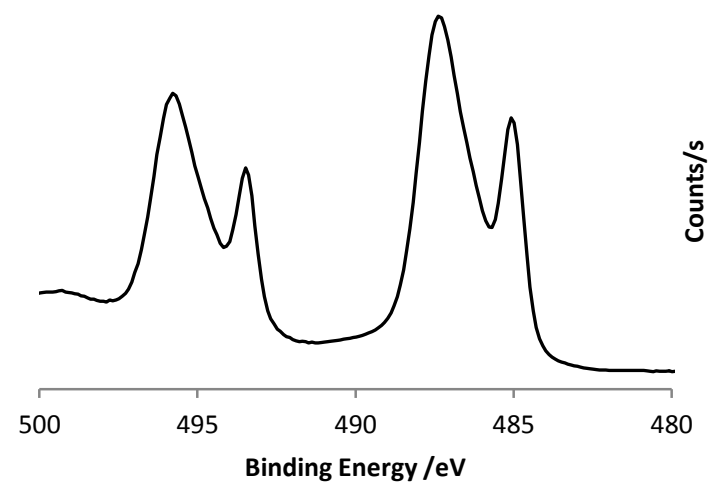

b) $0 \mathrm{~V}$

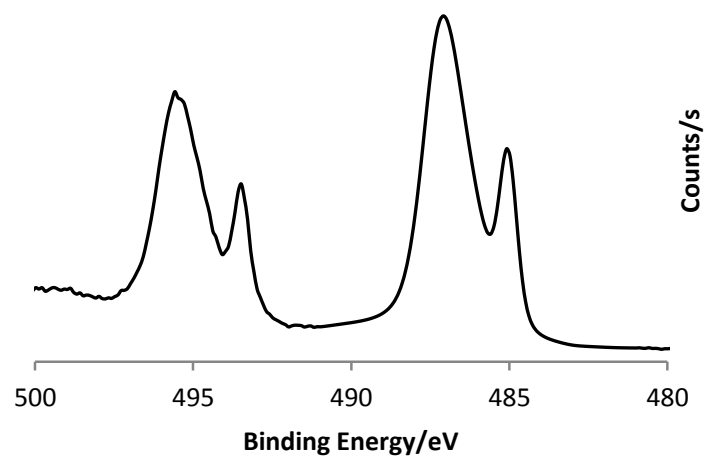

d) $-0.5 \mathrm{~V}$

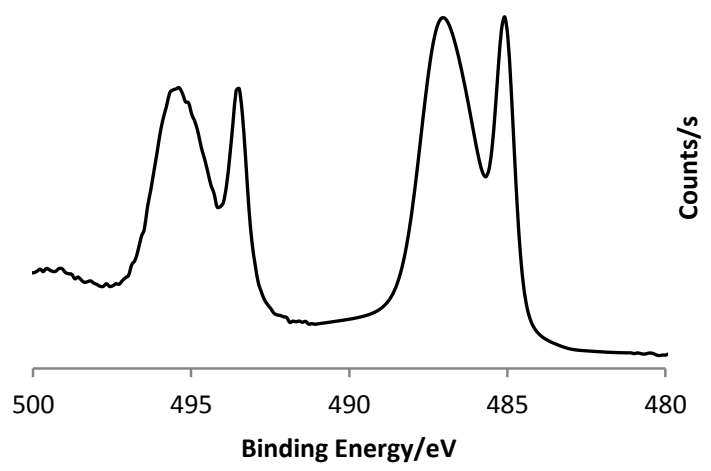

f) Native

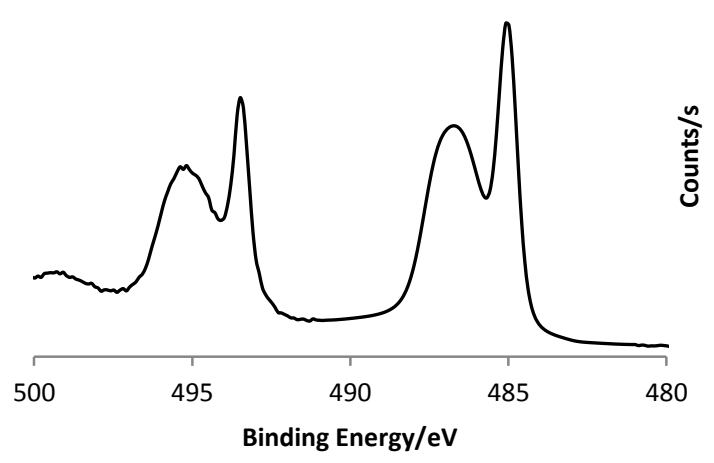

Figure [2] XPS high resolution Sn 3d scans of $5 \mu \mathrm{m}$ tin electrodeposits on copper electrochemically oxidised in a potassium bicarbonate-carbonate solution that had been stored at room temperature for $\sim 24$ hours. The charge passed was $30 \mathrm{mC} \mathrm{cm}{ }^{-2}$ : a) $1.2 \mathrm{~V}$ vs. SCE b) $0 \mathrm{~V}$ vs. SCE c) $-0.4 \mathrm{~V}$ vs. SCE d) $-0.5 \mathrm{~V}$ vs. SCE e) $-0.66 \mathrm{~V}$ vs. SCE f) native air-formed oxide 


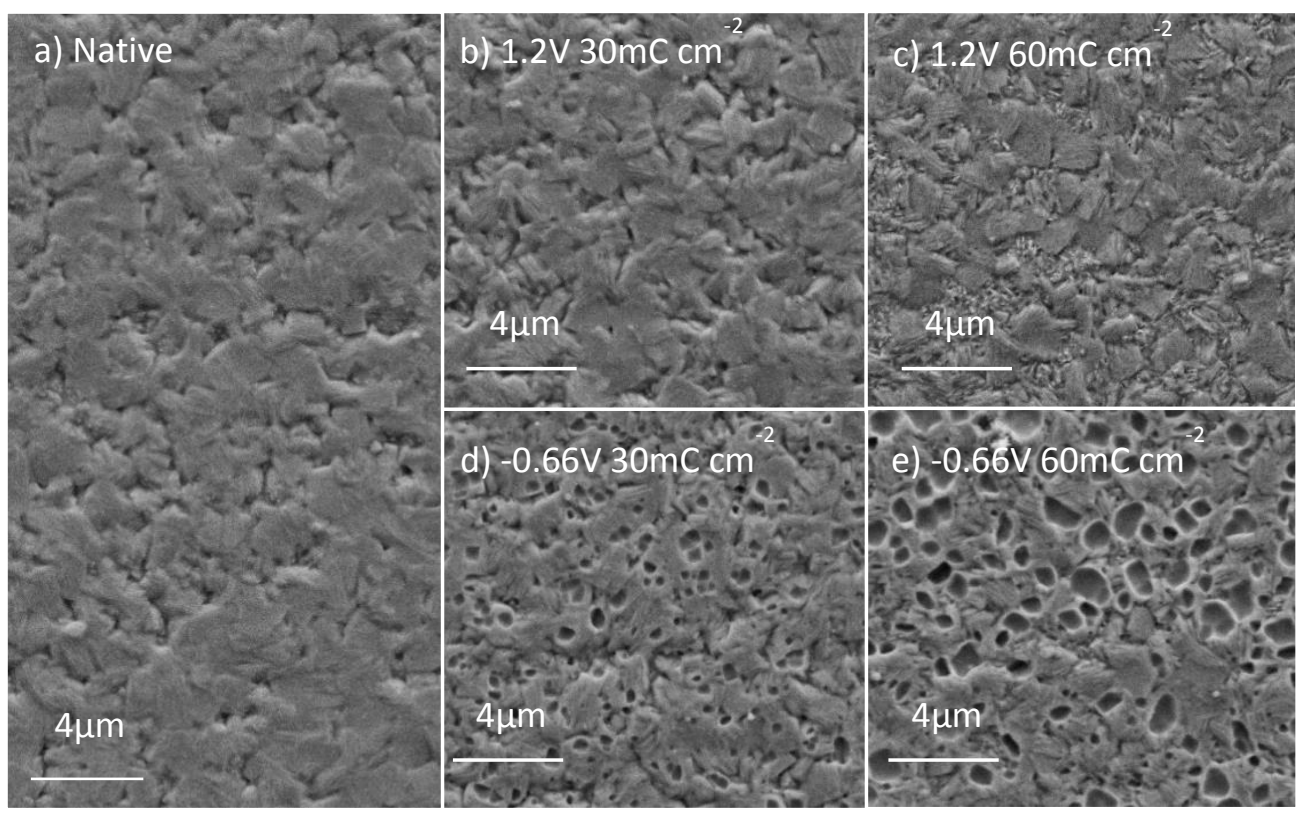

Figure [3] SEM micrographs showing the effect of electrochemical oxidation potential on the surface morphology of the electroplated tin, where a) a native air-formed oxide b) $1.2 \mathrm{Vvs} . S C E, 30 \mathrm{mC} \mathrm{cm}{ }^{-2}$, c) $1.2 \mathrm{Vvs}$.

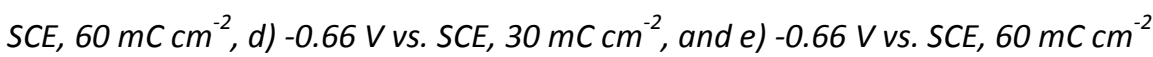




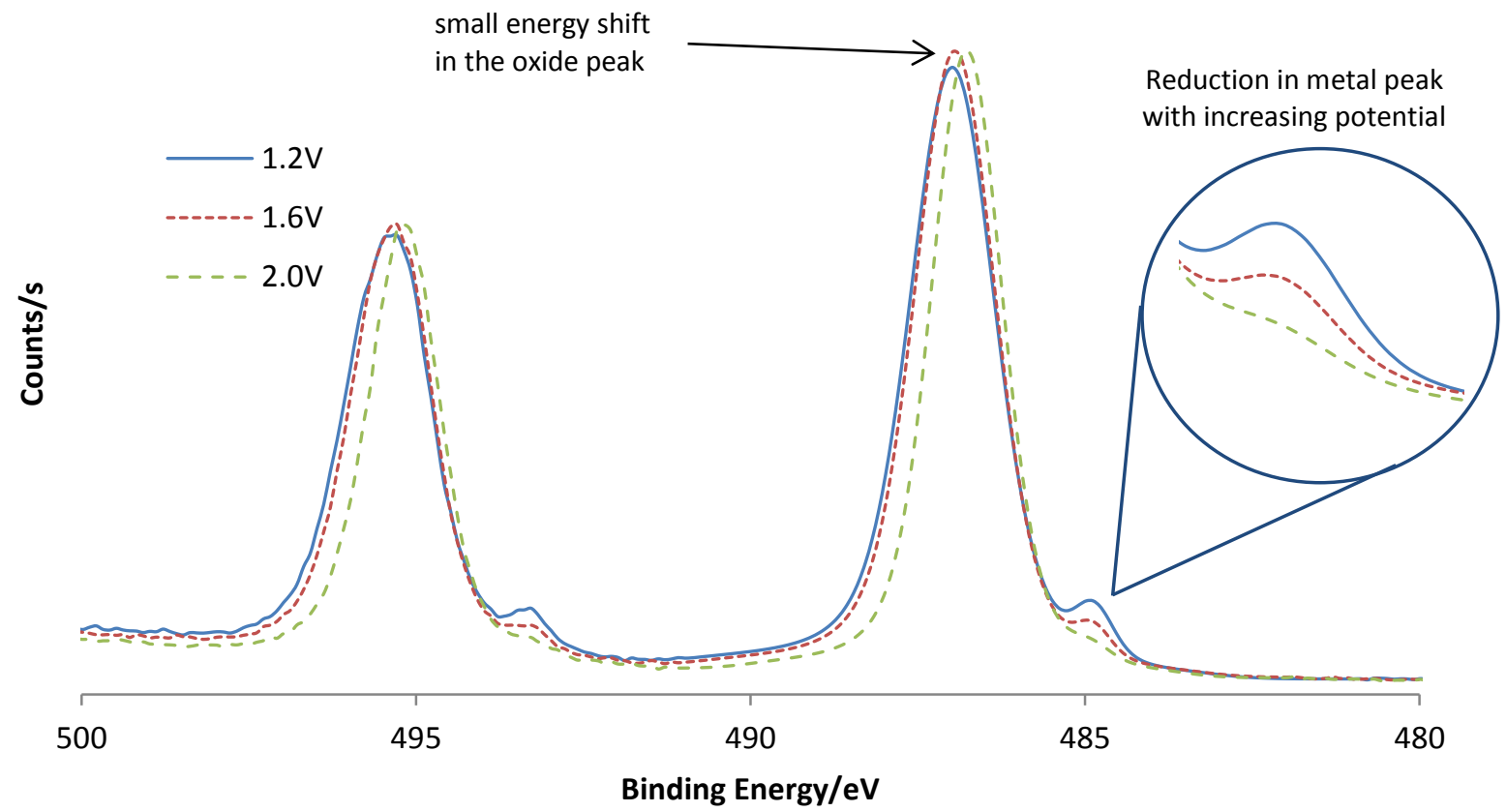

Figure [4] XPS high resolution scans of the Sn 3d peaks after electrochemical oxidation in a potassium bicarbonate-carbonate solution at potentials of $1.2 \mathrm{~V}$ (solid), $1.6 \mathrm{~V}$ (square dot) and $2.0 \mathrm{~V}$ (dash) all versus SCE 


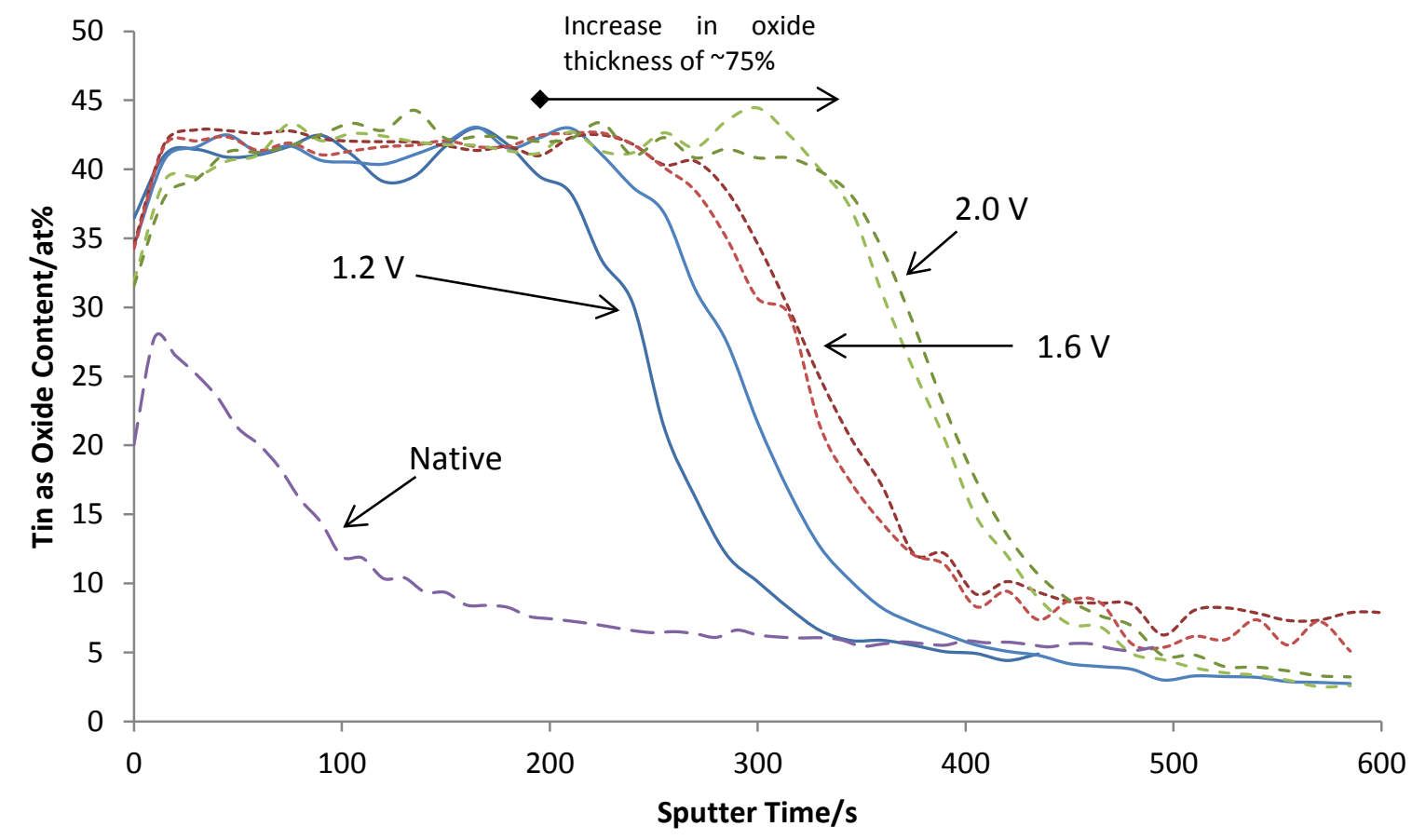

Figure [5] XPS depth profiles showing the distribution of $\mathrm{Sn}_{\text {oxide }}$ as a function of applied electrochemical oxidation potential 


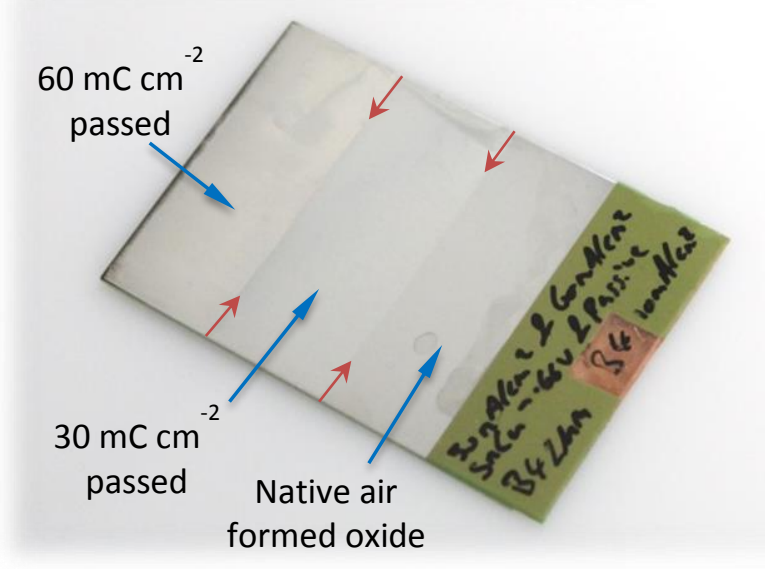

Figure [6] Test coupon used to investigate the effect of applied oxidation potential and charge passed on whisker growth 


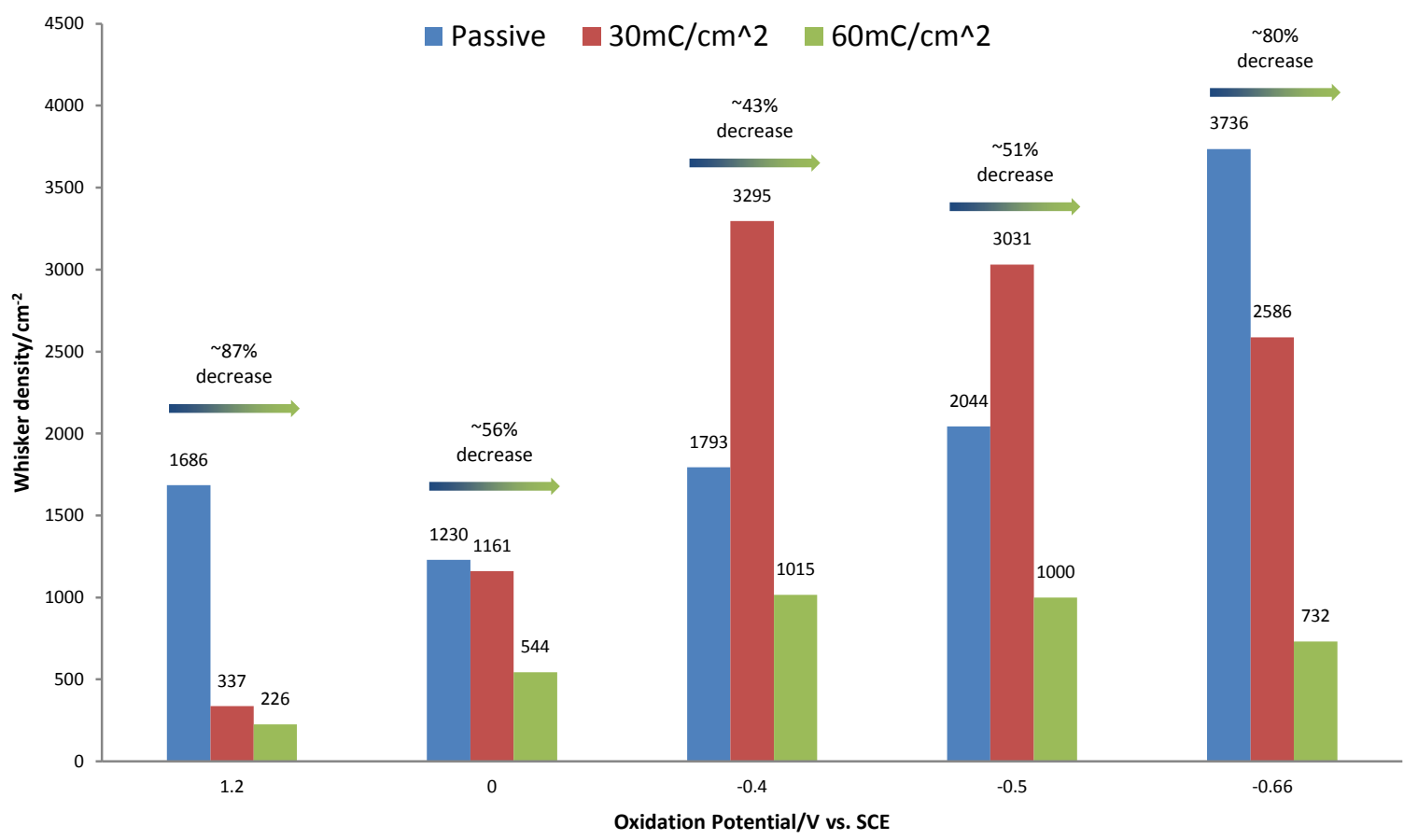

Figure [7] Graph showing the measured whisker density for electroplated tin samples electrochemically oxidised at different potentials after storage at room temperature for $\sim 2$ months. 
(a) Native oxide

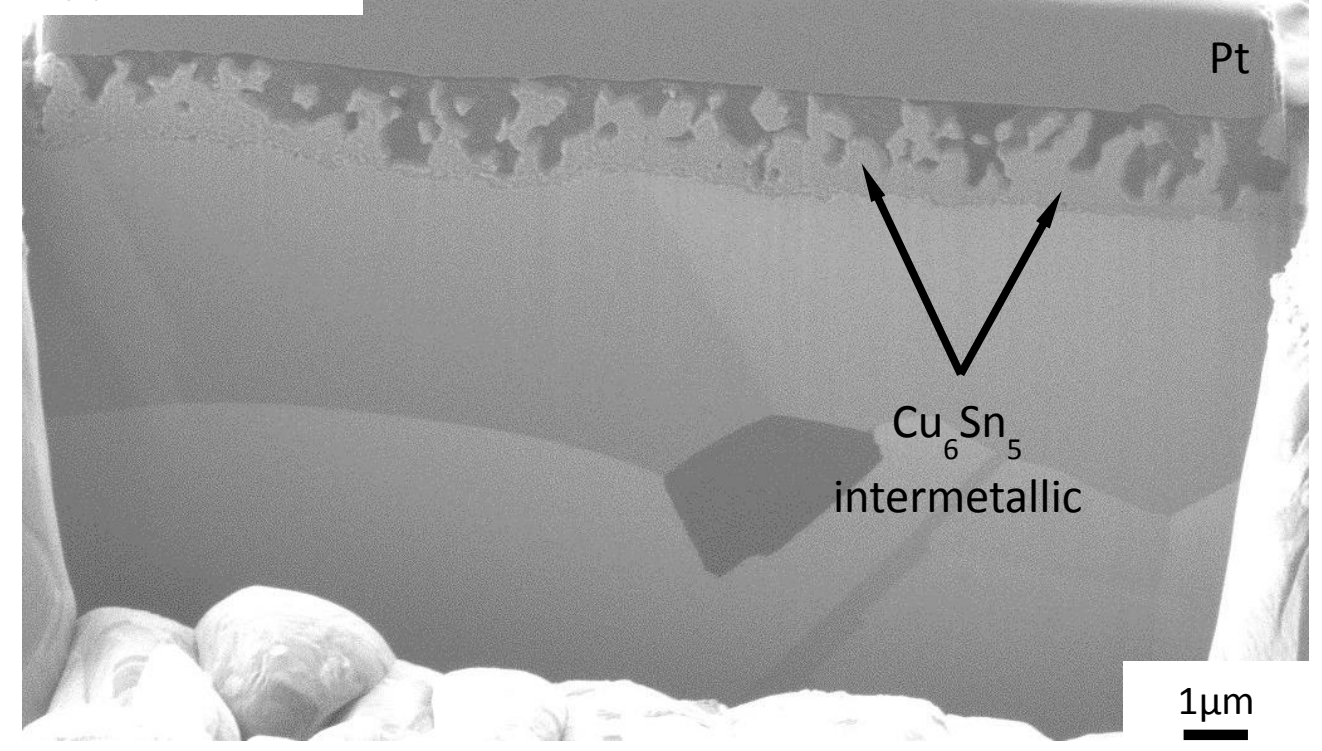

(b) Electrochemical oxidation at $1.2 \mathrm{~V}$

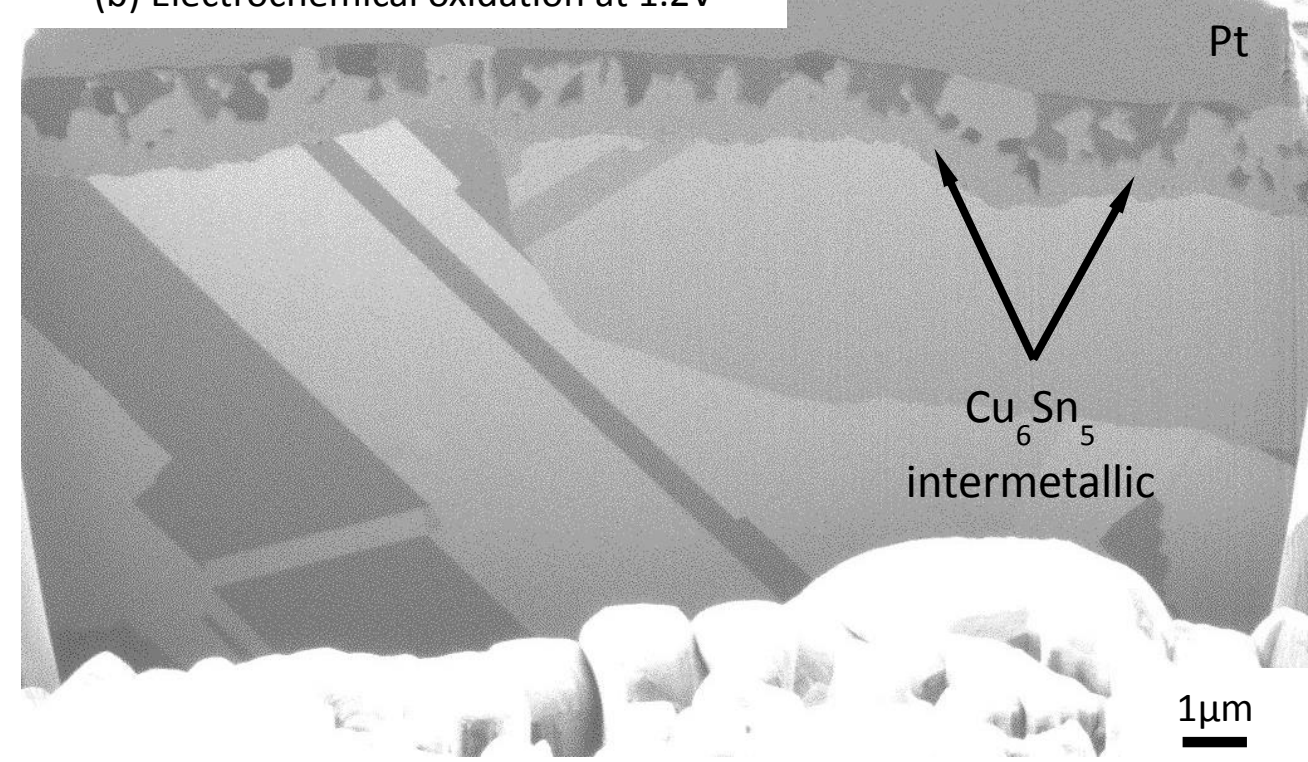

Figure [8] FIB cross-sectioned $2 \mu \mathrm{m} \mathrm{Sn-Cu} \mathrm{electrodeposits} \mathrm{on} \mathrm{Cu}$ after $\sim 24$ months of storage at room temperature, a) native air-formed oxide and b) oxide formed electrochemically at a potential of $1.2 \mathrm{~V}$ vs. SCE in potassium bicarbonate-carbonate 

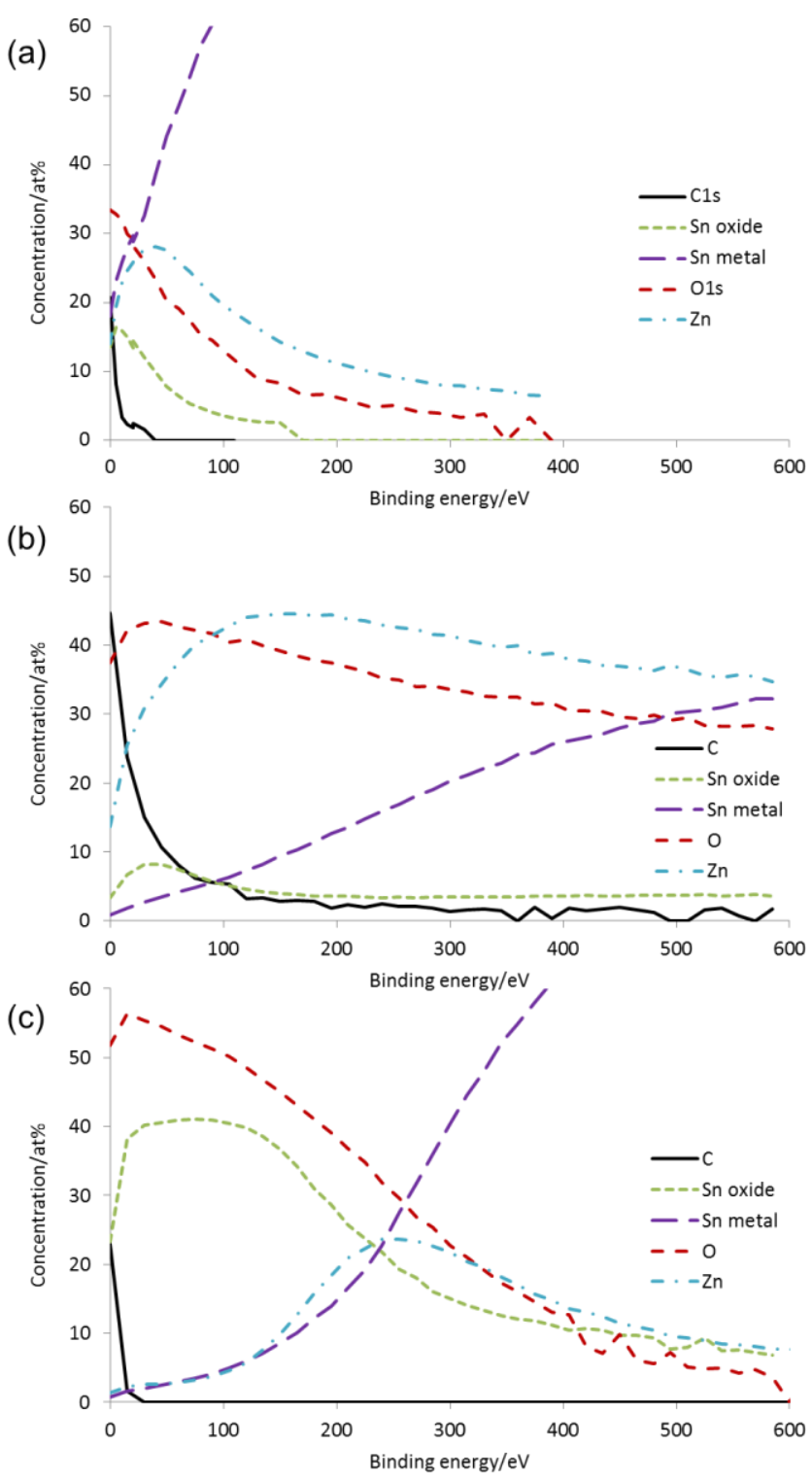

Figure [9] XPS depth profiles for Sn-Cu electrodeposits on Cu: a) 1 day old native oxide, b) native oxide after 24 months storage, and c) oxide formed electrochemically at a potential of $1.2 \mathrm{~V}$ vs. SCE in potassium bicarbonatecarbonate after $\sim 24$ months storage 


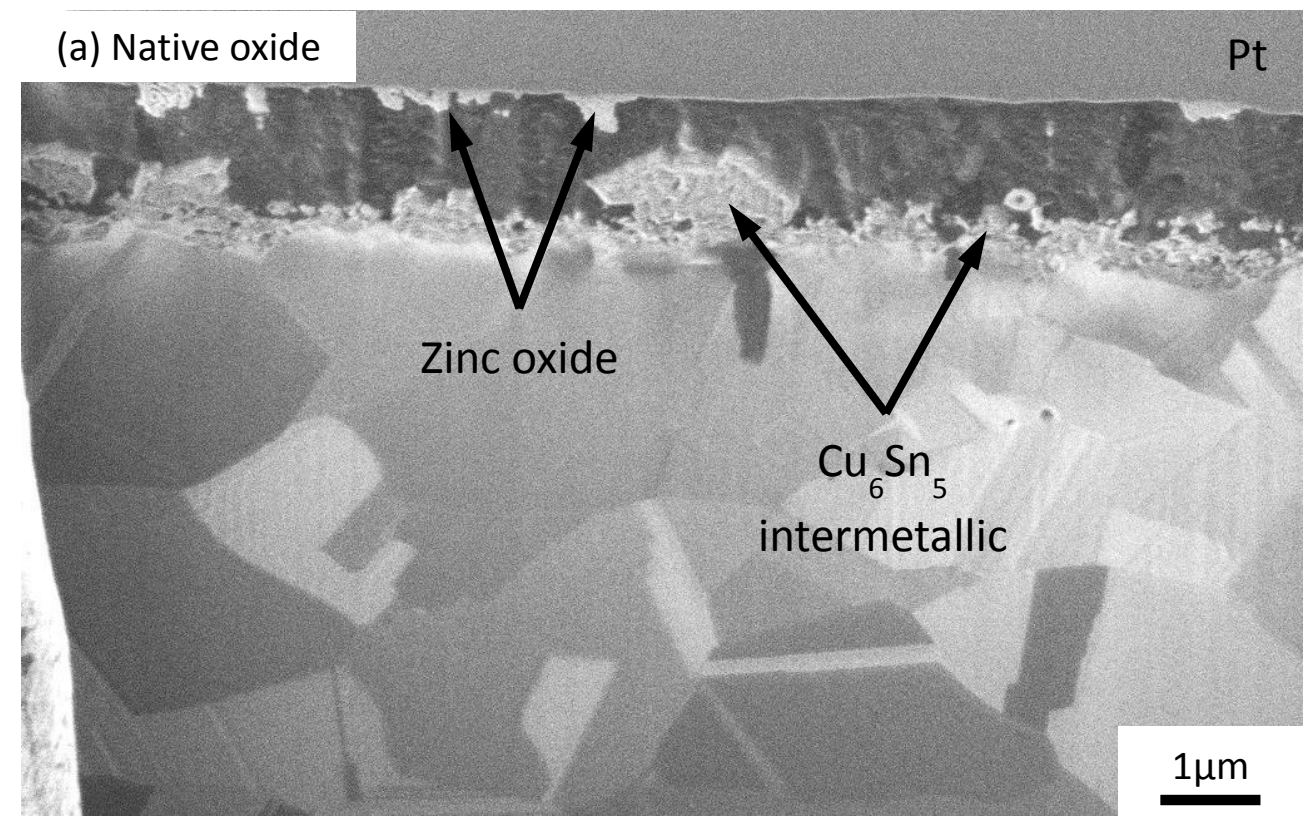

(b) Electrochemical oxidation at $1.2 \mathrm{~V}$

$\mathrm{Pt}$

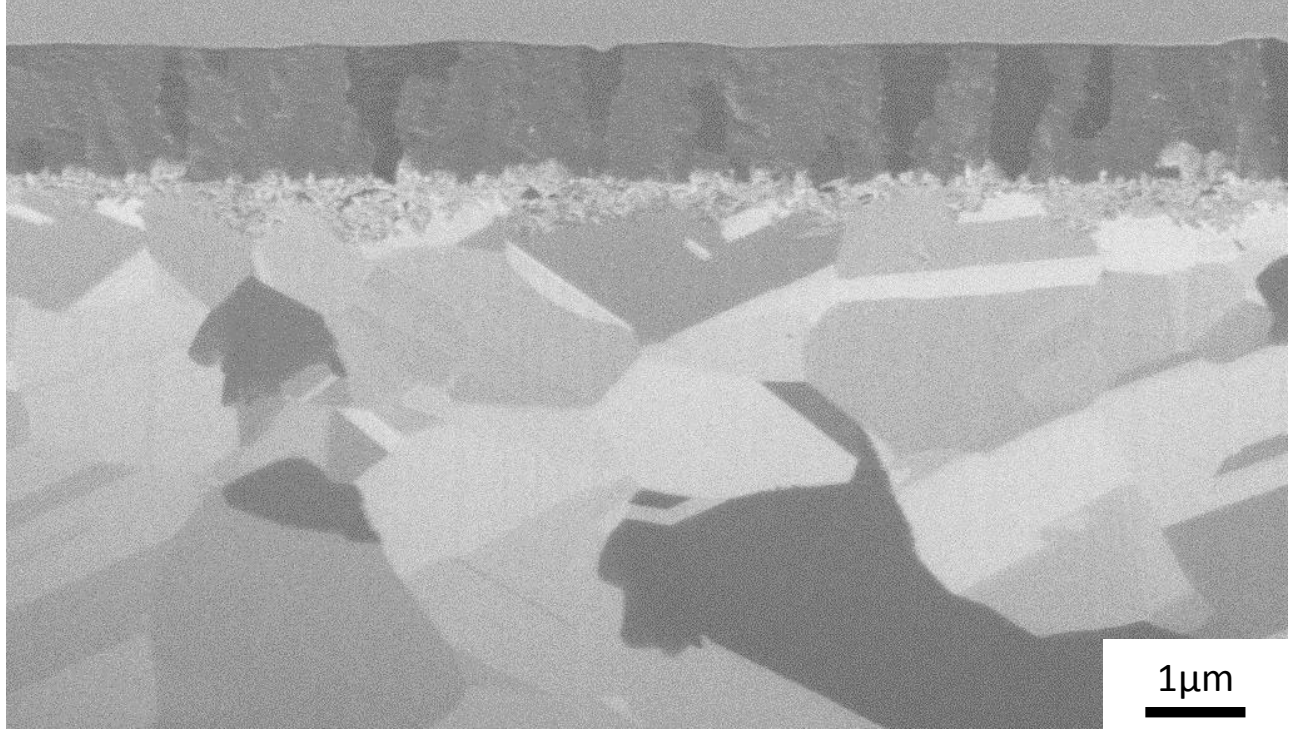

Figure [10] FIB cross-sectioned $2 \mu \mathrm{m}$ Sn electrodeposits on brass after $\sim 30$ months of storage at room temperature, a) native air-formed oxide and b) oxide formed electrochemically at a potential of $1.2 \mathrm{~V}$ vs. SCE in borate buffer 

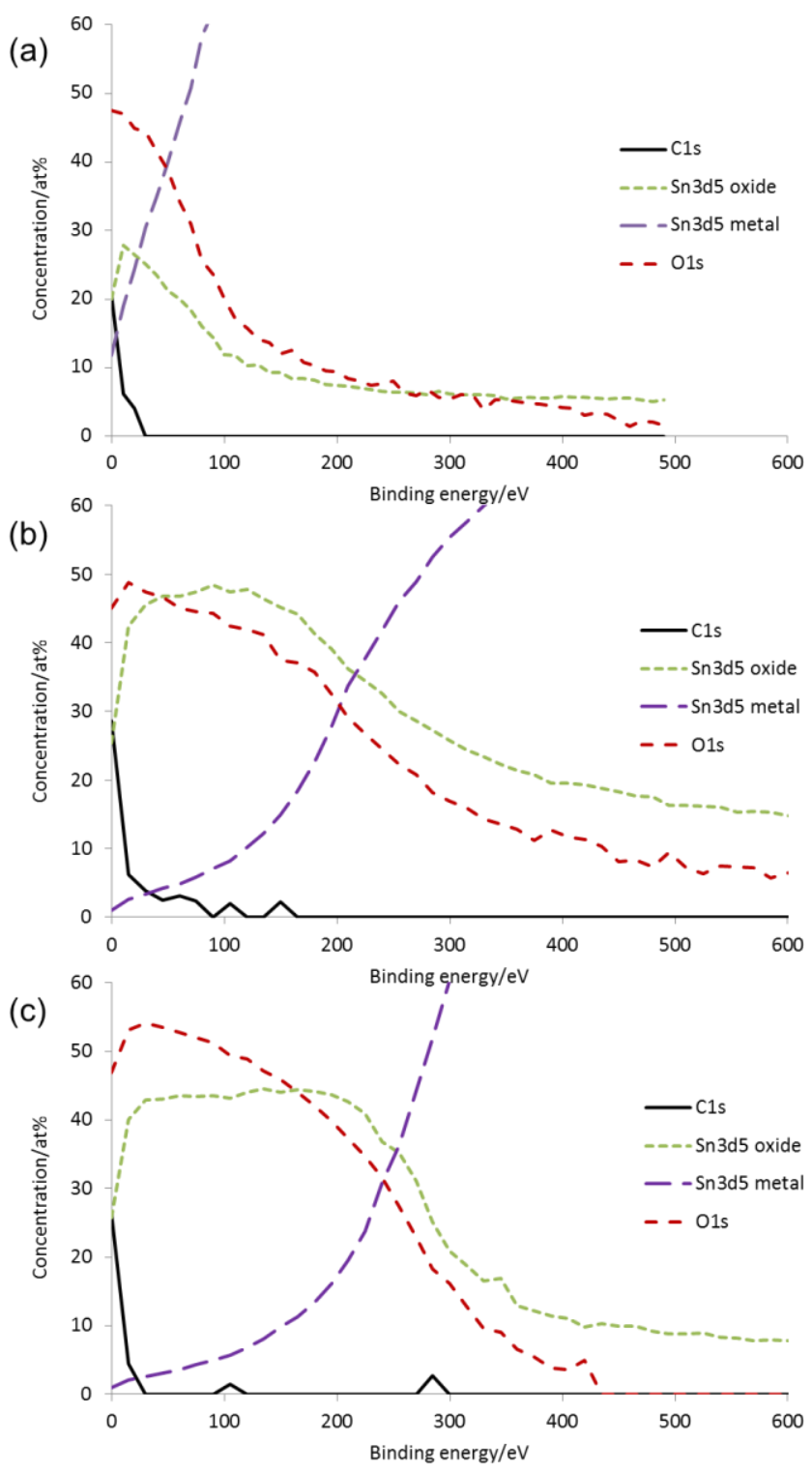

Figure [11] XPS depth profiles for $2 \mu \mathrm{m}$ Sn electrodeposits on brass: a) 1 day old native oxide, b) native oxide after $\sim 30$ months storage at room temperature, and c) oxide formed electrochemically at a potential of $1.2 \mathrm{Vvs}$. SCE in borate buffer after 30 months storage 